\title{
CULTURA CRISTIANA Y DERECHOS HUMANOS \\ Del MUNdo MEdieval a la Modernidad
}

\section{Gloria Cristina Flórez* \\ Universidad Nacional Mayor de San Marcos}

Fecha de recepción: septiembre de 2012 Fecha de aceptación: octubre de 2012

Resumen: El papel desempeñado por la Iglesia en materia de derechos humanos no es reciente. Sus aportes han sido muy importantes desde inicios de la era cristiana; sin embargo, existe un profundo desconocimiento del papel desempeñado por el cristianismo en el reconocimiento del derecho a la vida, a la paz y a la seguridad. En este trabajo se hará un recorrido histórico desde el mundo medieval y se analizará cómo la Iglesia ha insistido siempre en la defensa de la vida, la búsqueda de la paz, la justicia y el orden. Palabras clave: derechos humanos, cristianismo, justicia, historia de la Iglesia, actividad misionera, Edad Media.

ABstract: The role of the Church in relation to the Human Rights is not a recent issue. The Church's contributions have been important since the beginning of the Christian era, nevertheless there is a profound lack of

* Gloria Cristina Flórez es doctora en Historia por la Pontificia Universidad Católica del Perú y especialista en Civilización Medieval por la Universidad Católica de Lovaina. Actualmente es profesora en la Facultad de Ciencias Sociales de la Universidad Nacional Mayor de San Marcos y responsable de la Cátedra Ella Dunbar Temple para Profesores Visitantes en dicha facultad. Ha sido miembro del Consejo de Gobierno de la Universidad de Naciones Unidas (2004-2010). Entre sus publicaciones podemos mencionar Derechos Humanos y Medioevo: Un hito en la evolución de una idea (Lima: Fondo Editorial UNMSM, 2010). 
information of the role of Christianity in the recognition of the right to life, peace and security. In this work, we will make a historical journey from the medieval epoch and analyze how the Church has always insisted on the defense of life, the pursuit of peace, justice and order.

KeYwords: human rights, christianity, justice, church history, missionary activity, Middle Ages.

ueremos partir de la frase de Giorgio Filibeck del Consejo
Pontificio Justicia y Paz quien afirmaba que «los fieles católicos
no deben alimentar malsanos complejos de inferioridad o sentirse a)erios en el campo de los Derechos Humanos». ${ }^{1}$ En realidad, el papel desempeñado por la Iglesia no es reciente y sus aportes han sido muy importantes desde inicios de la era cristiana. Es necesario aclarar conceptos erróneos que se difunden fácilmente en nuestro medio, los cuales se presentan en sociedades, enfrentan múltiples problemas y plantean una serie de interrogantes respecto al mundo que deseamos para las generaciones futuras en relación con temas de gran actualidad: la religión y los derechos humanos.

Respecto a lo religioso, la historia nos ha mostrado los cambios vividos en el mundo occidental, desde la ruptura de la unidad religiosa cristiana en el siglo Xvi hasta llegar a las propuestas que negaban el papel de lo religioso en las sociedades en el siglo xx. Sin embargo, un reflorecimiento de la vivencia de lo religioso se ha presentado en las últimas décadas por múltiples razones y ha impulsado a los historiadores, creyentes o no, a

1 Droits de l'Homme. Recueil de Documents du Magistère de l'Église Catholique, p. II. 
interesarse en el tema. En cuanto a los Derechos Humanos, reconocemos la larga $\mathrm{y}$, en muchos casos, difícil trayectoria vivida para lograr su reconocimiento en una serie de documentos internacionales, especialmente la Declaración Universal de Derechos Humanos de las Naciones Unidas de 1948.

Nos había interesado como medievalista el estudio del papel desempeñado por la Iglesia en los movimientos en favor de la paz entre los siglos x al XII en Europa occidental (Cf. Florez 1990). También comprobamos a falta de información sobre los antecedentes históricos de los Derechos Humanos en las diferentes publicaciones referidas al tema, así como reconocer la existencia de estos derechos solamente a partir de la Declaración de los Derechos del Hombre y del Ciudadano (1789), si bien no se deja de reconocer la importancia de ciertos logros anteriores como la Petición de Derechos, el Acta del Habeas Corpus e, inclusive, la Carta Magna, impuesta por los barones ingleses a Juan sin Tierra en 1215 y considerada como el precedente más antiguo. (Cf. Ishay 2004 y Hunt 2007).

Observamos que la preocupación de los especialistas en los Derechos Humanos estaba centrada en lo jurídico o en lo político, más que en lo histórico $y$, salvo excepciones, no existían mayores referencias al mundo medieval (Cf. Perez-Prendes 2003; González 2002) o, en todo caso, se consideraba solamente la violencia de ese período, ${ }^{2}$ como las Cruzadas o la Inquisición. Así existía un profundo desconocimiento del papel desempeñado por el cristianismo en el reconocimiento del derecho a la vida, a la paz y a la seguridad, hoy en día considerados derechos humanos fundamentales.

2 Un ejemplo es la obra de divulgación de Sean McGLYNN, A hierro y fuego. Las atrocidades de la guerra en la Edad Media (Barcelona: Crítica, 2009). 
Necesitamos conocer el papel que ha desempeñado nuestra religión al moldear profundamente la civilización occidental y proporcionar una importante parte de nuestro bagaje cultural. Nuestra sociedad —en gran parte desacralizada y, sobre todo, laicizada - ha vuelto a la mayoría de sus integrantes poco interesados por lo religioso. Sin embargo, se reconoce, en estos últimos ańos, que es posible detectar motivaciones religiosas en los comportamientos de nuestras sociedades.

El cristianismo es una religión que tiene como característica esencial inscribirse en la historia, lamentablemente poco estudiada o más grave aún, muy mal comprendida, inclusive por sus propios seguidores. Una serie de circunstancias en el siglo xx — trágicas algunas - han llevado a nuevas aspiraciones, renovaciones hasta en los no católicos. Sin embargo, es necesario tener en cuenta que pese a las diversidades confesionales de hoy, el cristianismo ha ejercido y ejerce aún un predominio fundamental.

Es importante precisar -como lo han señalado destacados especialistas- que «lo religioso es un hecho social» (Le Goff 1988:7) y que tiene la particularidad de ser un compromiso individual (personal, íntimo, fuera del control social), y al mismo tiempo es una manifestación colectiva (búsqueda de expansión en el espacio, formación de comunidad). Esa vivencia religiosa no está aislada del espacio y tiempo en que se desarrolla, puesto que refleja las preocupaciones, los problemas y los intereses de su época y, más interesante aún, influye también en su época especialmente en dos datos esenciales: lugar sagrado y tiempo sagrado.

Siendo el fenómeno religioso un elemento de larga duración, necesitamos conocer su desarrollo en líneas fundamentales y tener en cuenta los planteamientos de Cristo, buscando una situación social diferente, basada en un principio fundamental, el «ágape» o caridad, que significa solidaridad, vocación de servicio, preocupación por los niños, la familia, los 
pobres y la paz, pero pide, sobre todo, una actitud diferente en el corazón, espíritu y mente. Nuestro análisis debe tener en cuenta el respeto mostrado por el cristianismo, desde sus inicios, respecto a las autoridades, como se manifiesta en los Evangelios y, especialmente, en el capítulo XIII de la Epistola a los Romanos de san Pablo. Si bien ese pensamiento reconoce la importancia que tiene la obediencia cívica para los cristianos, no debemos olvidar que ellos integran un grupo religioso exclusivista y proselitista, que debe suprema obediencia a Dios y da importancia al reino espiritual.

Ese mensaje puede considerarse verdaderamente revolucionario en una sociedad muy preocupada por valores ligados a lo material: fuerza, riqueza, belleza y poder. Los cristianos buscan que haya unidad, fraternidad, solidaridad y armonía entre los seres humanos, que la mujer sea compañera con igualdad de derechos, considera a los esclavos o servi iguales en dignidad a los libres y da enorme valor al trabajo.

La iglesia como institución ha tenido desde sus inicios una destacada actividad misionera y sus integrantes se preocuparon por todo lo que era asistencia social a los enfermos, los pobres, los ancianos, los huérfanos y los presos. Es importante, sobre todo, la actitud de defensa de la vida que ha tomado desde ese momento la Iglesia, así como la condena respecto al abandono y la exposición de los niños. Sin embargo, el grave problema de la esclavitud sigue presente puesto que no se busca la desaparición de ese estatus, salvo en casos excepcionales. Se prohíbe que los esclavos sean maltratados y en tal caso, se sanciona a los culpables con penas eclesiásticas y la Iglesia considera a libres y esclavos iguales en dignidad.

El ascenso del cristianismo en la sociedad romana en la época imperial es importante, si bien vive situaciones difíciles entre los siglos I al III por las persecuciones de algunos emperadores. Gracias al Edicto de Milán, en el año 313, se logra que Constantino el Grande le conceda la 
libertad de culto. A partir de ese momento ejerce una enorme influencia al suavizar las costumbres existentes. Entre los logros se pueden señalar los siguientes: otorgar libertad a los esclavos ante los obispos, mejorar la condición femenina respecto del jus liberorum, prohibir que se atente contra la vida de los niños — se los venda o prostituya—, posibilitar la retención de los niños desamparados, ayudar a la manumisión de los esclavos e impedir que a los matrimonios esclavos se los separen cuando sean vendidos, impedir que se marque el rostro de los condenados, dificultar los divorcios, salvo causa legal y conseguir que los domingos descansen los tribunales y no se realicen labores manuales. Asimismo, la Iglesia buscó también la prohibición de ciertos espectáculos, como el de los gladiadores, aunque sin éxito, la abolición de la muerte por crucifixión, el castigo del rapto como delito de violación y la obligación a los hijos de cumplir con los deberes filiales correspondientes.

El emperador Teodosio mediante el Edicto de Tesalónica (el año 380) convierte al cristianismo en la religión oficial del Imperio Romano y concede el jus liberorum a las mujeres, la liberación de ciertos reos en Pascua y la observación dominical se hace obligatoria, y — gracias a la influencia de san Ambrosio- se establece una prudente espera de 30 días para ejecutar a los sentenciados a muerte. Dentro de este período debemos ubicar la obra de san Agustín, La Ciudad de Dios, fundamental para conocer el pensamiento cristiano en sus diferentes aspectos. Esta elaboración ideológica plantea la existencia de dos ciudades: la celestial y la terrenal, la doble naturaleza humana, la lucha presente entre dos principios opuestos y donde san Agustín señala que «la paz es solamente posible en la ciudad celestial» (san Agustín) porque «la paz completa es imposible en la tierra y el poder terreno es inestable» (san Agustín), de esta manera se comprende la continua presencia de luchas en la ciudad terrenal. 
En este período ha sido muy importante la influencia del cristianismo en el derecho familiar de la época. Esto se comprueba en nuevos logros, como la disminución de la patria potestas (potestad paterna) y la dominicas potestas (potestad del amo); la protección de la sucesión de los hijos de madre intestada, en caso de reclamación de la parentela masculina; la supresión definitiva de las cárceles privadas y la definición del rapto como crimen público a partir del año 420 .

Es importante conocer lo que sucede en Occidente a partir del siglo $\mathrm{v}$ con la atomización del Imperio Romano por la presencia de la primera oleada de migraciones bárbaras, que afectó, gravemente, la romanización existente, sobre todo, en lo relacionado con la concepción de «poder»o "potestad pública». La idea de Estado como un organismo, concepto que contiene, define, coordina los derechos y deberes de los individuos y grupos, forzándolos a su cumplimiento y respeto, se encuentra totalmente ausente. Por lo tanto, el gobierno territorial en virtud de una soberanía verdadera con el fin de lograr el bien común, es totalmente desconocido.

Se presentan desde entonces los problemas causados por la difícil convivencia de grupos bastante diferentes, la llamada «barbarie política», es decir, la pérdida de la noción de Estado y, más grave aún, la confusión entre dos esferas de actividad: la civil y la eclesiástica; lo que es comprensible, si tenemos en cuenta que el tránsito al denominado mundo medieval no ha sido fácil, siendo necesario el apoyo de la iglesia, institución que cuenta con el prestigio de lo sagrado y lo intelectual, que le permite reemplazar a las autoridades imperiales, actuar frente a los bárbaros, tomar en sus manos el control de las ciudades y adquirir un papel dirigente.

Este es el ambiente en el que se presentan las primeras doctrinas políticas elaboradas por la Iglesia y que tienden a restringir, considerablemente, la competencia del poder temporal. Su ideología era el 
producto de argumentos religiosos y bíblicos, pero utilizando el lenguaje jurídico romano, especialmente importante en sus relaciones con Bizancio o Imperio Romano de Oriente, cuya ideología denominada comúnmente «Cesaropapismo» se expresaba así: un Dios, un Imperio, una Iglesia. Entre ambas ideologías no había conciliación posible, como podemos observar en la comunicación del Papa Gelasio I (492-496) a Anastasio I, basileus bizantino:

El mundo es gobernado por la autoridad sagrada pontificia y por el poder real. Estas dos jurisdicciones, desiguales en naturaleza y prestigio son independientes entre sí, aquellos que las ejercen tienen su potestad directamente de Dios. En lo espiritual, los reyes son hijos de la Iglesia, como tales, sometidos a ella. En los asuntos temporales y políticos, los Pontífices están subordinados a los príncipes. Ambos deben colaborar en la realización de la obra divina [...] (Quillet 1972:128).

Esta «teoría de las dos espadas» es la primera enunciación clara del concepto de soberanía en la cristiandad occidental. El Papa tiene Auctorictas (dirige y da forma), mientras que el Emperador tiene solamente la Regia Potestas (ejecuta); la solución la va a encontrar una de las figuras destacadas de la época, el Papa Gregorio el Grande (590-604), consciente del papel que tiene en Occidente expresa que «el poder terrenal está al servicio del poder papal, la fuerza pública tiende a un fin, pero su sentido se encuentra únicamente dentro de un orden cristiano", con esta afirmación dio el viraje necesario para lograr la realización de la «primacía papal» en la Edad Media, con la concepción de la autoridad espiritual como preeminente, limitándose la competencia real a la potestad de imponer la palabra de Dios. 
Ese período largo y doloroso — aproximadamente dos siglospermite la unión entre el poder civil y el poder eclesiástico, así como entre cultura y religión, y de profundas transformaciones económicas y sociales, especialmente la presencia de múltiples status jurídicos, disminuye la esclavitud y aumenta el número de siervos, situación con ciertas ventajas, al parecer por influencia de la iglesia. El amo pierde el derecho de vida o muerte, adquiriendo ciertas ventajas como por ejemplo la mayor productividad o la mejor relación con sus dependientes inferiores.

Ese mundo medieval tiene dificultad en distinguir claramente lo profano y lo sagrado, y sus vivencias religiosas no podemos verlas con los ojos de nuestra época. La Iglesia se apoya en una larga tradición, que se remonta a la época de los apóstoles y que le permite asistir a los necesitados, obligación que jamás dejó de cumplirse. Se respeta el derecho de los pobres, porque Dios lo quiere para su orden y por su justicia, inclusive hay una evolución en la concepción del pobre, a quien se lo sacraliza en sí mismo al margen de su concreta condición profana. La iglesia cuenta con armas poderosas de castigo que son la excomunión y el entredicho. La primera se utiliza para los jueces abusivos con los humildes porque la obligación de los obispos es proteger a los débiles y asistir a los desamparados.

A fines del siglo vi existe la institución conocida como «matrícula de los pobres», surgida en el mundo occidental desde la época de san Agustín y se relaciona con la basílica, es la lista o matrícula de los que debían ser asistidos por la iglesia, gracias a la ayuda proveniente de la limosna de los fieles. Pero, no bastaba auxiliar a los necesitados como expresión de solidaridad colectiva por parte de los ricos, sino que se debe ayudar al pobre porque «es el mismo Cristo». Los obispos cuentan, además, con el apoyo del monaquismo porque las abadías son refugios donde ha podido sobrevivir la cultura, gracias a la labor de los monjes, quienes en los talleres de escritura 
copiaron las obras clásicas y cristianas y enseñaron en sus escuelas durante siglos, moldeando así los monjes benedictinos durante siglos la cultura occidental.

Durante el período carolingio observamos importantes logros en lo político, como la restauración del Imperio, apoyado en una idea, que debe mucho al sabio Alcuino de York y con tres elementos: un principio romano, la realización por los francos y el dinamismo proporcionado por el cristianismo. La educación, la evangelización y la moral son importantes, pero existen problemas que deben resolverse como: la relación con el Papado, la guerra y el ideal cristiano de salvación de los súbditos como tarea de los gobernantes.

En este último aspecto se presenta un problema, puesto que el bien común, que debía lograr el poder público, se lo identifica con el fin espiritual y es lo que muchos autores denominan Agustinismo Político. No obstante, conviene aclarar que la tendencia a considerar al Imperio como «la Ciudad de Dios» en vía de realización es, según el mejor estudioso del tema Yves Congar «un agustinismo bastardo», basado en el Antiguo Testamento, el mito de Imperio y la doctrina gelasiana, borrando la distinción entre espiritual y temporal, confundiendo ambos planos, probablemente debido a la práctica de la unción real y a la falta de cultura que francos y sajones quienes no entendieron la sutileza del pensamiento de san Agustín: el ideal de la ciudad celestial se realizaría en el futuro y durante su vida terrenal el hombre pertenecía a la ciudad terrenal, si bien tendía a la celestial ${ }^{3}$

Lo anterior se confirma cuando revisamos la obra De institutione regia (El oficio de rey) escrita por el obispo Jonás de Orleans (¿760-842?),

3 Informaciones de Dom N. Huyghebaert en sus clases de Historia Eclesiástica en sus clases del Institut d'Études Médiévales de la Universidad Católica de Lovaina. 
(el oficio de rey), dirigida a Pipino I, rey de Aquitania. Es un pequeño tratado que le recuerda al monarca sus obligaciones hacia su padre y hacia el pueblo cristiano. Se refiere a la colaboración armoniosa del rey con los obispos, permitiendo realizar las exigencias concretas del pueblo cristiano y ofrece también una relación de los deberes del monarca respecto a los otros hombres afirmando que:

[...] el rey debe vigilar que el pueblo que le está sometido tenga abundancia de piedad, de paz, de caridad, de justicia y de misericordia, de concordia, de armonía y de todas las otras buenas obras, de manera que, teniéndolas sus súbditos merezcan tener al Señor con ellos.... El ministerio real es especialmente gobernar y dirigir al pueblo de Dios, con equidad y justicia y aplicarse a procurarle la paz y la concordia (De Orleans 197199).

La inestabilidad creada por la desintegración del Imperio Carolingio, el cual se vio afectado por el poder incrementado de los señores o dominus, enfrentados muchas veces entre sí y la inseguridad creada por la segunda oleada de migraciones bárbaras, ha dado lugar en Europa occidental a situaciones sumamente difíciles, especialmente para las poblaciones débiles o «inermes», como se las denomina, si bien muy numerosas, incapaces de hacer frente a los abusos y exacciones de los poderosos que cuentan con el poder de sus armas y la falta de control del poder central sumamente debilitado. 
El monarca, afectado por la pérdida de sus derechos conocidos como Regalia ${ }^{4}$ poseía todavía la fuerza que procede de la ceremonia de la consagración real que le confería al monarca poderes religiosos y mágicos (Cf. Bloch 1983). También le otorgaba la importante función de administrar la alta justicia, es decir, la relacionada con los delitos graves, la cual no delegó ni siquiera en los momentos de mayor debilidad.

La Iglesia cuenta con ciertas estructuras administrativas que muestran una gran cohesión, y sus miembros cuentan con prestigio en lo religioso y cultural. Especialmente tienen un papel importante las órdenes monásticas como Cluny, la labor de ciertos papas como Silvestre II y de obispos como Gerardo de Cambray y Adalberón de Laón, así como algunos centros intelectuales y artísticos. La Iglesia se convierte, por lo tanto, en la única institución capaz de establecer un cierto control en esos momentos, interesada en proteger a los débiles y lograr la paz en una sociedad donde la violencia está casi institucionalizada. Su acción se va a manifestar en los llamados Movimientos en favor de la paz: Paz de Dios y Tregua de Dios.

En esos movimientos en favor de la paz podemos distinguir 4 etapas o fases ligadas a épocas y situaciones bien definidas:

1. Episcopal, que ha establecido la paz de Dios, gracias a los concilios regionales o provinciales. El primero, reunido en Charroux, el 1 de junio del año 989, importante en lo cronológico como en lo geográfico, ha permitido a los obispos hacerse cargo de una de las tareas esenciales de la antigua justicia carolingia: el mantenimiento de la paz y la protección de los pobres y del clero. Entre los aspectos destacados del texto conservado observamos

4 Son los siguientes: suprema jurisdicción en lo militar, el ejercicio supremo de la justicia, el poder de crear y cobrar impuestos, el monopolio de acuńación de moneda y la participación en la designación y promoción de obispos. 
la preocupación de los signatarios frente a una violencia sumamente grave, no controlada a su debido tiempo; así como el interés en proteger bienes, personas y determinados lugares y el deseo de sancionar a los culpables de las infracciones en los tres cánones: Anatemas contra los violadores de iglesias, los que pillan los bienes de los pobres y los que atacan al clero.

Las autoridades eclesiásticas, el clero y los laicos de ambos sexos están de acuerdo en participar en una tarea útil para la comunidad. Se trata de reparar los errores cometidos y suprimir la violencia presente por doquier, así como proteger a los débiles y a ciertos bienes. Las autoridades eclesiásticas consideran que la debilidad de la monarquía les permitía tomar en sus manos, la tarea de mantener la paz y, sobre todo, ella posee los medios para hacerla respetar mediante las sanciones o los castigos eclesiásticos.

Este es el inicio de los movimientos por la paz y el orden que se han desarrollado ampliamente y sus cánones o decisiones se adaptaron y evolucionaron, conforme a los cambios que afectaron a la sociedad en los siglos siguientes. Su primera fase ha tenido una duración de aproximadamente 30 años con gran influencia en las regiones meridionales. Su origen está en la zona cercana a Poitiers y se apoya en los Concilios o Sínodos, así como en los juramentos para lograr la paz y el orden. Su interés por la «paz» está relacionado con el deseo de lograr la salvación eterna de los participantes, de allí la importancia de las sanciones o castigos para quienes incumpliesen el juramento. Un dato interesante es la coincidencia cronológica de la Paz de Dios con el ascenso de los Capetos al poder monárquico y el apoyo que prestaron al Movimiento los príncipes y, sobre todo, los personajes ligados al poder episcopal. 
2. Juramentos de Paz, que se inician el año 1020 y tienen una duración de 20 años aproximadamente. Las fórmulas del Juramento son importantes porque crean obligaciones a quienes lo prestan, similares a aquellas del sistema feudo-vasallático. Sin embargo, este Juramento puede prestarlo toda persona, tal como había sido el juramento de fidelidad carolingia, sin las restricciones del contrato feudo-vasallático. Debemos prestar especial atención al juramento del obispo Garín de Beauvais el año 1023 y a las prohibiciones que establece como algunas que señalamos:

-No invadiré una iglesia de ninguna manera. En razón de su asilo, no invadiré tampoco las bodegas situadas en el recinto de una iglesia [...]

-No tomaré el buey, la vaca, el cerdo, el carnero, el cordero, la cabra, el asno o la leña que lleve, la yegua y su potro no domado. No tomaré al campesino o a la campesina, a los sargentos o a los mercaderes; no les tomaré sus dineros, no los obligaré a pagar rescate; no los arruinaré, tomándoles su haber bajo pretexto de la guerra de su señor, y no los azotaré para quitarles su subsistencia. -No atacaré al mercader ni al peregrino, y no les despojaré, salvo si cometen un daño. -No mataré el ganado de los campesinos, sino únicamente para mi alimento o el de mi escolta.

-No capturaré al campesino y no le quitaré su subsistencia por instigación pérfida de su señor.

-No atacaré en ausencia de su marido a las mujeres nobles, ni a quienes circulen con ellas, a menos que las encuentre cometiendo algún delito contra mí, por su propio impulso; y observaré la misma actitud con las viudas y las monjas. 
Ese documento proviene de una región vecina a la Ile de France (dominio de los monarcas franceses) y permite constatar el progresivo debilitamiento del poder central, así como el valor y eficacia del juramento, en especial, la relación que guarda con las mentalidades de la época.

3. Asociaciones o ligas en favor de la paz, que se inician el año 1038, gracias a la intervención del arzobispo Aimon de Bourges, el primero en tomar la iniciativa de establecer el compromiso de todos los hombres, mayores de 15 años, quienes prestan juramento de hacer respetar la paz, declararse enemigos de los perturbadores de la paz y tomar las armas — contra ellosen caso sea necesario (Contamine 1986:435). Los transgresores de la paz eran castigados con la excomunión y el «interdicto», pero existe el interés de hacer respetar el juramento, mediante la presencia de milicias urbanas armadas por el poder episcopal, inclusive en ciertas regiones como el Condado de Barcelona, la intervención del poder público está claramente señalada (García de Valdeavellano 1982:404).

En ciertos casos, las Asociaciones o Ligas en favor de la Paz han sido únicamente defensivas o de socorro mutuo, si bien han existido asociaciones ofensivas que lucharon contra los violadores de la paz. Sin embargo, sus resultados no siempre fueron favorables a los grupos dirigentes que las apoyaron en sus comienzos, pues, dieron lugar a una serie de reivindicaciones populares e inclusive, favorecieron levantamientos contra los poderes señoriales, como la famosa revuelta de los encapuchados del Puy en 1182.

Asimismo, estas asambleas impresionantes han reunido alrededor de las reliquias de los santos a numerosos fieles, quienes formularon delante de los prelados un nuevo pacto con el Todopoderoso. Los gritos " ipaz, paz! » de la multitud han creado un clima propicio para suscitar la emoción, así como la convicción de obtener la salvación eterna, mediante 
su participación en el establecimiento de la paz y el orden. Sin embargo, una de las mayores innovaciones se ha presentado en la época de Luis VI de Francia. Son las llamadas Comunas, integradas por gentes de pueblo que han obedecido las órdenes de su soberano, sin originar los problemas de las milicias episcopales. Esta organización fundada en el respeto al Juramento no logró el fin deseado: impedir los desórdenes, pero, en cambio, tuvo una influencia muy importante en los comportamientos y mentalidades, es el caso de todo lo relacionado con la Caballería y la Cruzada.

4. Tregua de Dios, que es la etapa final y si bien no se discute la intervención del Abad Oliba de Santa María de Ripoll, obispo de Vich, en lo concerniente a su creación y difusión, se presenta un desacuerdo respecto a la fecha de origen, 1023 o 1033. Existen dos modelos de Tregua:

a) El modelo meridional, que ha tenido como punto de partida el Primer Concilio de Tuluges (Tuluyas o Toulonges), pueblo pirenaico en donde fue proclamada en 1027 la «Paz y Tregua de Dios». Este modelo meridional, muy influenciado por Cluny y difundido tanto en Cataluña como en el Sur de Francia, considera la protección de los «inermes», la prohibición de apoderarse de ciertos bienes, la utilización del juramento, la prohibición de guerras privadas durante ciertos días y la inmunidad de determinados lugares.

b) El modelo «más francés» (Poly 1991:244) es el monitorio de los obispos a los diocesanos, equivalente a la palabra paz, es una institución con desarrollo propio en regiones como el Monte Saint-Michel, Laón, Thérouanne entre otros y el juramento prestado impide las hostilidades entre los combatientes; muy pronto se extiende a las regiones septentrionales tomando características 
propias, como por ejemplo en Flandes, Normandía e, incluso en Inglaterra. La Tregua de Dios — sea en su modelo meridional o septentrional_ prohíbe los combates el día domingo (costumbre ya conocida en la época carolingia), luego incluyó otros días: jueves, viernes y sábados, así nos lo describe el monje Raúl Glaber:

En la misma época [1041], por inspiración de la gracia divina, primero en Aquitania, luego en todo el territorio de los galos, por temor y por amor de Dios, se comenzó a establecer un pacto, según el cual, del miércoles en la tarde hasta el alba del lunes siguiente, ninguno se permitiría temerariamente de tomar a nadie lo que sea por la fuerza, ni vengarse de un enemigo, ni incluso exigir la prenda de un garante. Quien se levantara contra este decreto público, lo pagaría con su vida o con la excomunión y el exilio. Se convino en llamar a todo esto, «tregua del Señor», en lengua vulgar, porque ella no reposaba solamente en las precauciones humanas sino era también garantizada por el temor de Dios [...]. (Glaber 1986: 295)

La medida se extendió posteriormente a ciertos períodos litúrgicos: Adviento, Navidad, Cuaresma, Pascua, así como al lapso comprendido entre las Rogativas y la Octava de Pentecostés, al igual que a las tres fiestas de la Virgen y sus Vigilias y a ciertas fiestas de Santos. Así, los días de combate se limitan a 211 por año y los combatientes tienen la posibilidad de realizar una forma de ascesis en su ocupación; teniendo en cuenta la importancia dada en la época a la purificación de las costumbres, a las prohibiciones alimentarias y a los peregrinajes a Jerusalén, Roma, Santiago de Compostela o Conques. 
El papado participa activamente en esta fase, ya sea en la época de Nicolás II o de Alejandro II, quienes buscan extender el movimiento, el cual se hizo universal a partir de la convocatoria de Urbano II a la Cruzada. El proyecto de este monje de Cluny se expresa el 27 de noviembre de 1095 en el Concilio de Clermont, un llamado propiamente religioso, desinteresado en sus orígenes y difundido rápidamente con mucho éxito. Ese llamado crea la «Mística de Cruzada» y el grito «iDios lo quiere!» ha sido repetido en dicha reunión por una multitud de aproximadamente 20 mil personas.

Nuestro balance de esos Movimientos reconoce el papel de la Iglesia como una fuerza social y espiritual de la época, la intervención pontificia manifestada en las decisiones tomadas en los Concilios Ecuménicos de Letrán en los siglos XI y XII y, especialmente, la clara influencia de los centros religiosos y sus autoridades, sin olvidar el apoyo recibido de las asociaciones, cofradías y grupos comunales. Ellos han respondido a la necesidad de paz y orden en una época de violencia, pero sus resultados se vieron limitados por diferentes razones, entre ellas, la oposición inicial de los señores y la recuperación del poder real, lo cual redujo la intervención eclesiástica en los asuntos relacionados con la paz, la justicia y el orden.

No obstante, hubo ciertos logros que repercutieron en lo cotidiano, como la limitación de la violencia incontrolable y la reglamentación de luchas como las guerras justas y torneos. A mediano plazo, los Movimientos han permitido la ascensión del grupo de los «caballeros» y el triunfo del ideal caballeresco, así como la elaboración de una ideología de «la guerra y de la paz», que consideraba a la guerra como un instrumento para mantener la paz, la justicia y el orden, canalizando la actividad guerrera hacia las cruzadas y los combates lícitos. A largo plazo, su influencia se ha manifestado en la legislación de ciertos países o regiones y en el desarrollo de la simbología y del ideal religioso (el santo militar por ejemplo). 
El desarrollo de estos movimientos ha coincidido con un período de expansión, caracterizado por el aumento demográfico, así como las mejoras en las condiciones desfavorables de los grupos urbanos y rurales. Se ha tratado de proteger su derecho a la vida y evitar toda violencia en su persona, especialmente para los más débiles, como se observa en los documentos otorgados en los dominios religiosos laicos y religiosos. Asimismo, se ha buscado mejorar la condición jurídica de los estratos campesinos, específicamente de los que estaban sometidos a la servidumbre o que no tenían un amplio goce de la libertad y esto se ve reflejado en el aumento de manumisiones de los siervos; las mejoras de las condiciones de los enlaces matrimoniales entre siervos de diferentes seńoríos; el aligeramiento o incluso la liberación de determinadas cargas serviles, especialmente los denominados malos usos o costumbres; el reemplazo del impuesto de capitación por derechos reducidos o diversas contribuciones; la reglamentación de la talla periódica en ciertas aldeas; la concesión de roturaciones que les permite a corto o mediano plazo mejorar su estatus jurídico. Se ha conseguido también que quienes incumplían con las medidas de protección fueran sancionados con penas eclesiásticas; en lo concerniente a los aspectos económicos, la protección de bienes muebles e inmuebles del campesinado, la prohibición de atentar contra los bienes de explotación campesina, así como de los animales necesarios para las labores agrícolas, la protección de las mercancías en tránsito, las mejoras en lo concerniente a los pagos por herencia, la reglamentación de las contribuciones en productos y especies, las indicaciones específicas para las contribuciones de gastos militares, la reglamentación de las jornadas de trabajo: horarios, duración y tipo de faenas que deben realizar y la disminución de contribuciones serviles. 
A las importantes libertades concedidas a las ciudades, se les agregan otras concesiones como el reconocimiento de espacios inviolables, especialmente religiosos, la inmunidad para ciertos personajes como los legados pontificios; la prohibición de atacar a los religiosos, funcionarios, mercaderes, mujeres, niños y peregrinos, en general, a los no combatientes; la ayuda a los necesitados en tiempo de dificultades ofreciéndoles alimentos y se ofrece protección en los hospitales a los enfermos, inválidos y mujeres encinta, a lo que se ańade, la alimentación que deben recibir como se observa en el Estatuto del Hospital de San Juan de Bruselas de octubre de 1211.

En el ámbito político, las relaciones entre los poderes laicos y religiosos deben hacer frente a dificultades por múltiples razones: la debilidad del régimen monárquico que debe coexistir con el fortalecido sistema feudovasallático, la teocracia pontificia afirmando su preeminencia sobre el poder temporal, gracias a las teorías políticas elaboradas en este período y que si bien reposan en principios morales y metafísicos buscan adaptarse a las situaciones de la época. La gran figura es la del papa Gregorio VII (10201085), quien busca la reforma total de la Iglesia y sobre todo liberar a las autoridades eclesiásticas de su dependencia frente al poder temporal.

Los monarcas consideran como tarea fundamental asegurar o conservar la paz pública, siendo los únicos responsables de ella, si esa paz se altera, se ofende al rey y él es quien debe tomar las medidas del caso y erradicar las fuerzas que impiden a la realeza continuar su existencia. Esa alteración se ha manifestado continuamente y de diversas maneras, sea en conflictos de limitada importancia o de magnitud más amplia en el tiempo o en el espacio como las Cruzadas, especialmente contra el Islam o también aquella contra los herejes cátaros o albigenses, estudiadas por numerosos especialistas. Por tal razón, los gobernantes de este período se encuentran íntimamente ligados a la guerra, actividad compleja y que debe considerarse 
como un «fenómeno cultural» porque nos permite estudiar las relaciones entre realidad y norma, entre práctica y ética, así como entre hecho y derecho.

Desde inicios de la Edad Media, la guerra ha sido tema de análisis, es el caso de Isidoro de Sevilla, quien en sus Etimologías reconoce cuatro clases de guerra: justa, injusta, civil y más que civil. La primera debía responder a alguno de los tres principios: vengar un agravio, expulsar al invasor o ser declarada por autoridades legítimamente constituidas. No obstante, en este período que estudiamos existe el deseo de analizarla en detalle y se logran elaboraciones cada vez más complejas como la Guerra Justa y la Guerra Santa, asimismo se pasa del rechazo a la aceptación e inclusive a la alabanza de la actividad guerrera. Los autores se preocupan por las causas, tipos y reglamentación de la guerra e incluso se busca deslindar todo lo referente a la paz, el orden, la felicidad y la virtud.

Es importante tener en cuenta como punto de partida la publicación, en 1140, del Decreto de Graciano, que señala las cuatro condiciones para la Guerra Justa: ordenada por el príncipe, sin la participación de los religiosos y en defensa de la patria o recuperación de los bienes robados con exclusión de violencia apasionada e ilimitada ${ }^{5}$. Teniendo en cuenta que esa sociedad tiene múltiples motivos para justificar las acciones armadas mediante el nombre de guerra justa e incluso santa, se debía dar importancia a los presupuestos espirituales en la argumentación que justificara la guerra ${ }^{6}$, último recurso para la defensa de una causa justa, siendo presentada la paz como un bien digno de alta estima.

5 Es importante esa consideración de Graciano respecto a esos límites.

6 Obras como la Summa Decretorum de Rufino y la Summa Coloniensis a mediados del siglo XII son prueban de ello. 
A partir del siglo XIII se observa la abundancia de obras referidas a la guerra justa. Por ejemplo, las de Johannes Teutonicus y San Raimundo de Peñafort señalan y difunden los cinco criterios clásicos de la guerra justa: persona, objeto, causa, espíritu y autoridad; especialmente la Suma Teológica de santo Tomás de Aquino, quien se preocupa por analizar la licitud de los diferentes casos de muerte o ejecución y las responsabilidades de quienes mandan ejecutar o matar, y considerar que el gobernante debe sentar las bases para la felicidad de los hombres, manteniendo la paz y el orden.

Estas propuestas deben enmarcarse dentro del importante marco cultural de la época y considerar el papel desempeñado por la Iglesia en la enseñanza en los siglos anteriores y, muy especialmente, el aporte de Silvestre II, «el Papa del año mil», al elaborar el plan de estudios en Reims reagrupando la gramática, la lógica y las matemáticas. Su impacto se manifiesta en la enseñanza de los siglos siguientes, especialmente en una institución cuyas proyecciones se manifiestan hasta la actualidad, es la Universitas, corporación de maestros y alumnos con el fin de promover el saber y difundirlo mediante la enseñanza y la investigación de sus miembros.

Esta institución pontificia cuenta con la etapa formativa de los Estudios Generales con los profesionales de teología, medicina y derecho y ha contribuido a la puesta en marcha de un ideal pedagógico y a la formación de profesionales en las diferentes ramas del saber. Esos intelectuales tuvieron un papel clave en los importantes cambios que se presentaron a partir del siglo XII al elaborar teorías de separación neta entre el poder civil y el poder religioso, que permiten afirmar la autoridad suprema del monarca y la idea de Estado, quebrando el ideal teórico del Imperio como Estado único y superior a todos. Asimismo, la universidad contribuye con la formación de los «burócratas», personal especializado que reemplaza a los antiguos colaboradores clericales en la administración del naciente Estado Moderno. 
Los siglos finales de la Edad Media nos interesan por la presencia de importantes transformaciones que al combinarse con elementos subsistentes del período anterior dan lugar a la llamada Modernidad. La gran depresión que se inicia en 1315 incide en los diferentes ámbitos y transforma los diversos estamentos existentes, así como en las actividades económicas y la situación de crisis se hace sentir también en la política nacional e internacional. Una situación muy diferente se hace presente con las modificaciones necesarias para la Génesis del Estado Moderno en lo concerniente a la naturaleza del lazo entre gobernantes y gobernados, el nacimiento de un espacio nacional, la guerra, el modo de gobierno con una burocracia especializada y la dinámica intelectual.

Debemos tener en cuenta que la intensificación de la guerra fue un componente obligatorio y estructural del sistema porque es el pretexto para la tributación y también el instrumento esencial de la redistribución de la extracción económica. Esta guerra del Estado tiene tres caracteres originales: justa, lícita y que hace necesaria la profesionalización de las milicias y se observa un cambio en lo concerniente al impuesto de fines del siglo XIII, respecto a la tributación feudal derivada del concepto de auxilio. El impuesto estatal representa una novedad y también una ruptura: se cobra al conjunto de súbditos, pero necesita el acuerdo del cuerpo social o de las facciones dominantes, asimismo la demanda debe parecer legítima en su pretexto, en su forma y en su monto. Si bien el impuesto puede aportar mucho al Estado tiene un precio político que es la necesidad del consentimiento y de la adhesión del cuerpo social.

Interesa el gran número de obras que se refieren a la guerra justa y los libros de la paz, como los de Cristina de Pisan o Georges Chastellain, menos conocidos que el famoso Defensor de la paz de Marsilio de Padua, el primer gran teórico del Estado quien afirma «[...]por lo cual debemos 
desear la paz, buscarla si no la tenemos, encontrada guardarla y, con todo el empeño, rechazar la contraria discordia. A ella cada uno de los hermanos ha de contribuir, y mucho más las agrupaciones y comunidades entre sí, tanto por el afecto de la caridad como por el vínculo o el derecho de la sociedad humana» (1988:56), mientras que Guillermo Occam, franciscano inglés, rechaza el poder arbitrario, considerando que la autoridad debe ejercerse por el bien común y debe resistirse a la coacción.

Sin embargo, debemos referirnos a otros documentos que nos permiten comprobar una clara preocupación por adquirir mayor seguridad en la vida cotidiana como son las condiciones de trabajo y salariales de los artesanos, las mayores seguridades para los comerciantes y sus bienes, la protección al medio ambiente, la representatividad de los súbditos en las asambleas representativas, entre otros. Esa sociedad caracterizada en los siglos anteriores por su carácter gregario (Cf. Duby 1974: 208-209)), va a adquirir un carácter cada vez más individualista, es el nacimiento del espíritu laico en los momentos en que la Iglesia incrementa el deseo de mayor control en la ortodoxia o la ortopraxis de sus fieles, utilizando una serie de mecanismos como la práctica sacramental o la vigilancia institucional. Sin embargo, nuevos actores intervienen en la conducción de las sociedades, dando lugar a una difícil relación entre el poder civil y el poder religioso en los siglos siguientes, lo que va a fomentar en las sociedades modernas la elaboración de una propaganda negativa de la Iglesia Católica y, por ende, de la Edad Media, resaltando todos aquellos aspectos como la Inquisición o las Cruzadas, vistos como atentatorios a los avances de un mundo en progreso se hayan convertido en símbolos del atraso y abuso del cristianismo. De allí, la importancia de analizarlos dentro del contexto y con la perspectiva de su época y, sobre todo, difundir todas las contribuciones del cristianismo y la Iglesia Católica, sean las que hemos presentado sucintamente o aquellas 


\section{CULTURA CRISTIANA Y DERECHOS HUMANOS}

que tienen lugar a partir del siglo XVI, insistiendo siempre en la defensa de la vida, la búsqueda de la paz, la justicia y el orden. 


\section{BIBLIOGRAFÍA}

Bloch, Marc

1983 Les rois thaumaturges. Paris: Gallimard.

Contamine, Philippe

1986 La Guerre au Moyen Âge. Paris: Presses Universitaires de France.

Duby, Georges

1974 «Le Moyen Âge»En Aujourd'hui l'histoire, Paris : Éditions Sociales.

De Orléans, Jonas

1995 Le métier du roi. Paris: Éditions du Cerf.

Flórez, Gloria Cristina

2010 Derechos Humanos y Medioevo: Un hito en la evolución de una idea. Lima: Universidad Nacional Mayor de San Marcos [contiene la bibliografía completa del tema].

1999 «De la sociedad feudal a la génesis del Estado Moderno en Europa Occidental» Agenda Internacional, revista del Instituto de Estudios Internacionales de la Pontificia Universidad Católica del Perú, año VI, N. 12. Lima.

1998 «Los Derechos Humanos en los inicios de la sociedad feudal (siglos XI-XIII)». En Agenda Internacional, Revista del Instituto de Estudios Internacionales de la Pontificia Universidad Católica, año V, N. 10. Lima. 
1990 «Los Movimientos a favor de la paz, mil años antes de la Declaración de los Derechos Humanos», Edición Conmemorativa del Cuadragésimo Aniversario de la Declaración Universal de los Derechos Humanos. Lima: Ministerio de Justicia.

García de Valdeavellano, Luis

1982 Curso de Historia de las instituciones españolas. Madrid: Alianza Editorial.

García Fitz, Francisco

2003 La Edad Media. Guerra e ideología. Justificaciones jurídicas y religiosas. Madrid: Sílex.

Glaber, Raoul

1986 Histories. Turnhout: Brépols.

Head, Thomas and Richard Landes (eds.)

1987 «Essays on the Peace of God: The Church and the People in Eleventh-Century France». Historical Reflections, fall, Vol. 14, N. 3. Waterloo.

1992 The Peace of God. Social Violence and Religious Response in France around the year 1000. New York: Cornell University Press.

Hunt, Lynn

2007 Inventing Human Rights-A History. New York/London: Norton \& Company. 
Ishay, Micheline

2004 A History of Human Rights. From the Ancient Times to the Globalization Era. London: University of California Press.

Le Goff, Jacques y René REMOND

1988 Préface de "Histoire de la France religieuse, T. I. Des dieux de la Gaule à la Papauté d'Avignon. Paris:Éditions du Seuil, pp. 7ss.

Poly, Jean-Pierre et Eric Bournazel,

I99 I La mutation féodale. Paris: Presses Universitaires de France.

Quillet, Jeannine

1972 Les clefs du pouvoir au Moyen Âge. Paris: Flammarion. 